\title{
Tiến sĩ 'lạc điệu'
}

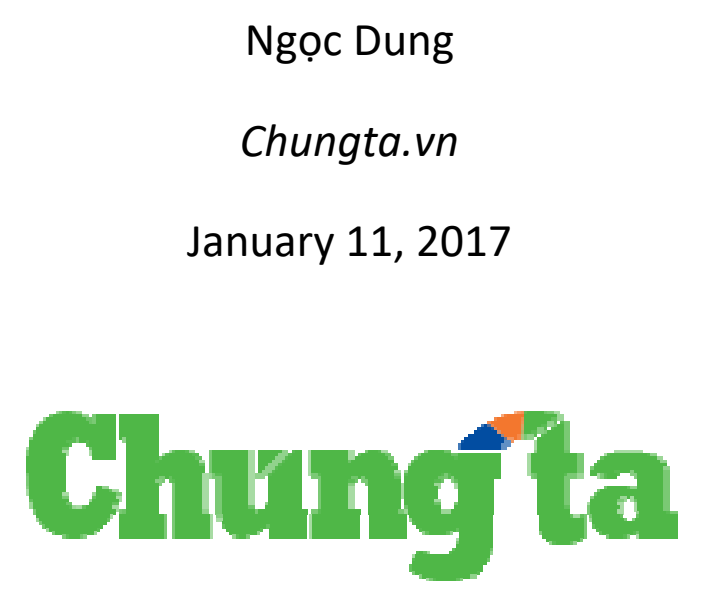

https://chungta.vn/nguoi-fpt/tien-si-lac-dieu-1111091.html 


\section{Chung ta}

Thứ tư, 11/1/2017 | 13:55 GMT+7

In trang $(\mathrm{Ctr}+\mathrm{P})$

\section{Tiến sĩ 'lạc điệu'}

Hoàn thành nghiên cứu sinh tiến sĩ ở Bỉ, anh Vương Quân Hoàng về nước, "lao đầu" vào các nghiên cứu về vốn, chứng khoán, giao dịch... Năm 2007, anh đã gọi chứng khoán Việt Nam là thị trường trên mây và đưa ra nhưng cảnh báo trong khi cả thiên hạ đang cuồng say với "vũ điệu" của lĩnh vực móri mẻ này.

Những cảnh báo sớm của anh chỉ được chú ý khi sự đổ vỡ của thị trường diễn ra vào hơn một năm sau và những "ám ảnh" của nó vẫn còn đến tận hôm nay.

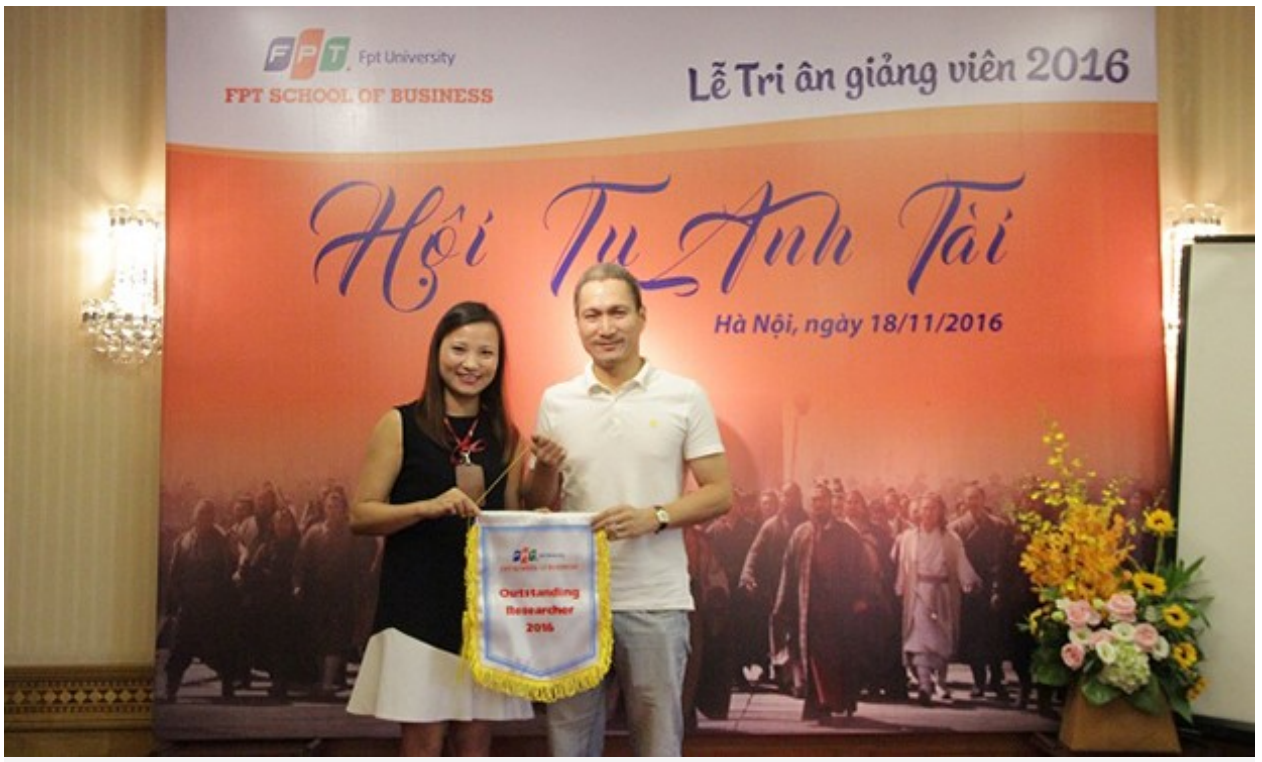

TS. Vương Quân Hoàng nhận giải "Outstanding Researcher 2016" (nhà nghiên cứu nổi bật) của Viện Quản trị Kinh doanh FPT.

Vương Quân Hoàng là thế, anh sẵn sàng dội gáo nước lạnh khi người ta tin vào đỉnh cao của thị trường chứng khoán, bất động sản. Khi cả nước lo thiếu tiền để phát triển kinh tế, anh chỉ lo "ngộ độc" vì lắm nguồn lực đầu tư mà năng lực sử dụng thì kém. Năm 2016, khi câu chuyện tiến sĩ lương 3 triệu đồng được nhắc như một cái cớ giải thích cho việc nhà khoa học Việt có quá ít công bố quốc tế, anh nói thẳng tiền không có nhiều ý nghĩa trong câu chuyện nghiên cứu khoa học. Có thể 
coi anh là một tiến sĩ "lạc điệu" với những phương châm sống đã làm nên thương hiệu của mình như "sống để làm việc chứ không phải để hưởng thụ" hay "trường đại học phải là nơi sản xuất ra những tri thức, đó là những công trình nghiên cứu của các giảng viên, nghiên cứu sinh".

TS. Vương Quân Hoàng hiện là giảng viên Viện Quản trị Kinh doanh FPT (FSB). Năm 2016, anh có tới 18 công trình nghiên cứu được công bố trên các tạp chí khoa học quốc tế, trong đó có 10 bài báo đứng tên ĐH FPT. Đây là mục tiêu anh tự đặt ra cho mình khi đầu quân về trường vào tháng 6/2016.

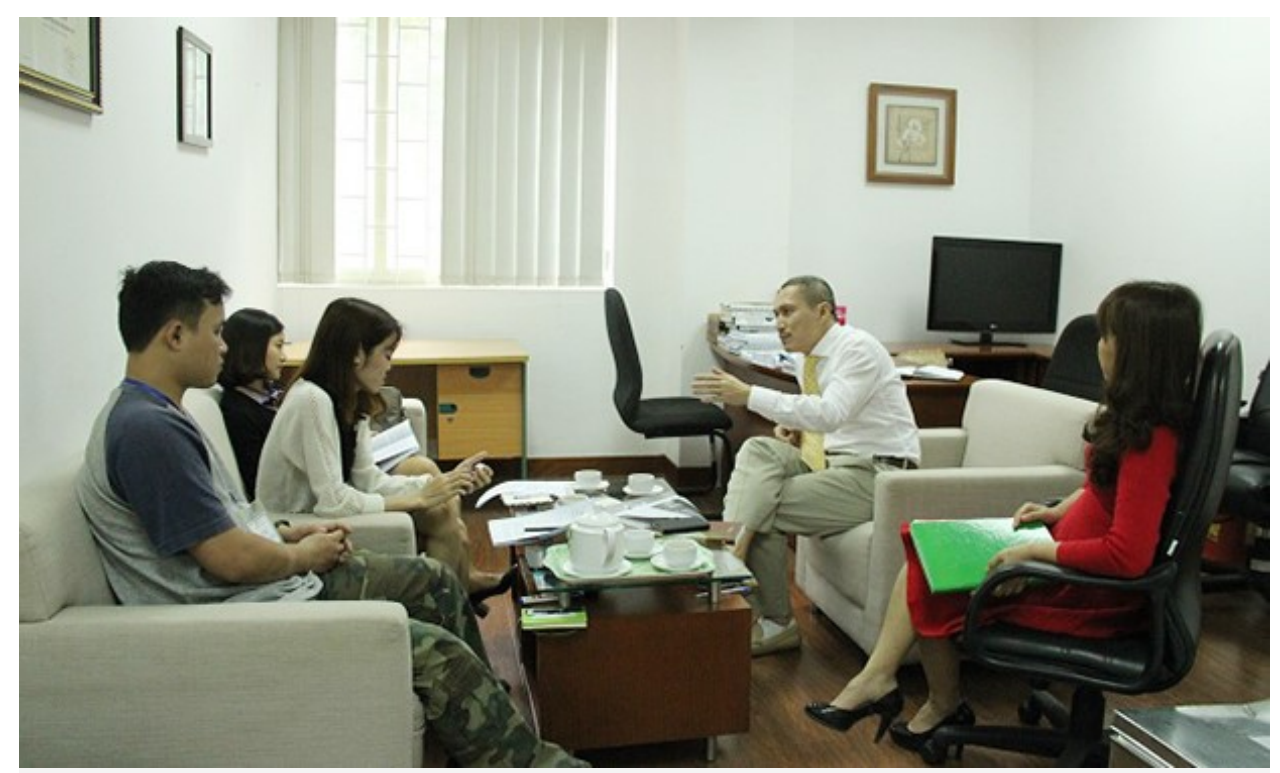

Anh Hoàng luôn sã̃n sàng chia sẻ về các công trình của mình. Anh là một trong những giảng viên tiên phong và khơi dậy phong trào nghiên cứu khoa học trong nội bộ giảng viên của FSB và Tổ chức Giáo dục FPT.

Sau nhiều năm nghiên cứu về các hiện tượng thuần túy kinh tế, những công bố khoa học của anh những năm gần đây ngày càng "đời" hơn, đi sâu vào tìm hiểu những đặc tính của nền kinh tế trong nước, mối liên hệ giữa kinh tế và các lĩnh vực xã hội khác. Trong năm nay, anh tập trung vào hai mảng chính gồm Kinh tế y tế (Health Economics), chứa đựng các vấn đề về quản trị sức khỏe công, y tế cộng đồng, các yếu tố kinh tế - xã hội của y tế dự phòng và Năng lực khởi nghiệp trong nền kinh tế Việt Nam.

Ở địa hạt nghiên cứu mới mẻ này, anh Hoàng lại có những kết luận đầy bất ngờ'. Công trình công bố quốc tế về 4 xóm bệnh nhân ở Việt Nam cho thấy những con người ở đây càng tuyệt vọng hơn khi được xã hội hỗ trợ bằng hiện vật và có cảm 
giác như mình nhận của thừa, đứng bên lề xã hội. Trong thực tế, những người bệnh này cần tiền hơn.

Câu trả lời của khoa học và số liệu có thể làm nhiều nhóm hoạt động xã hội cảm thấy chạnh lòng và thực tế các nhóm này ở Việt Nam vẫn hoạt động khá tự phát, dựa vào cảm tính. Anh Hoàng cho biết: "Tâm lý của những người bệnh nhận hỗ trợ có nguyên nhân kinh tế sâu xa: trong khủng khoảng con người cần tính thanh khoản (tiền mặt) cao". Anh Hoàng còn có nghiên cứu về xác xuất khánh kiệt của bệnh nhân Việt Nam dựa vào các dữ liệu thống kê.

Chia sẻ về câu chuyện tiền bạc trong nghiên cứu khoa học, anh Hoàngbảo: "Khi bạn bắt đầu nghĩ đến tiền, bạn không làm được gì nữa, đặc biệt là trong lĩnh vực khoa học, sáng tạo, thậm chí là cả kinh doanh".

Anh Hoàng cho rằng đối với một số ngành khoa học tự nhiên sẽ cần phòng thí nghiệm hiện đại nhưng nếu đổ lỗi vì thiếu tiền, thiếu cơ sở vật chất nên không có nghiên cứu đột phá thì không nên. Bởi nếu người nghiên cứu có công trình tốt và năng lực thực sự, cơ hội thực tập, hợp tác ở các phòng thí nghiệm hiện đại bậc nhất thế giới luôn rộng mở.

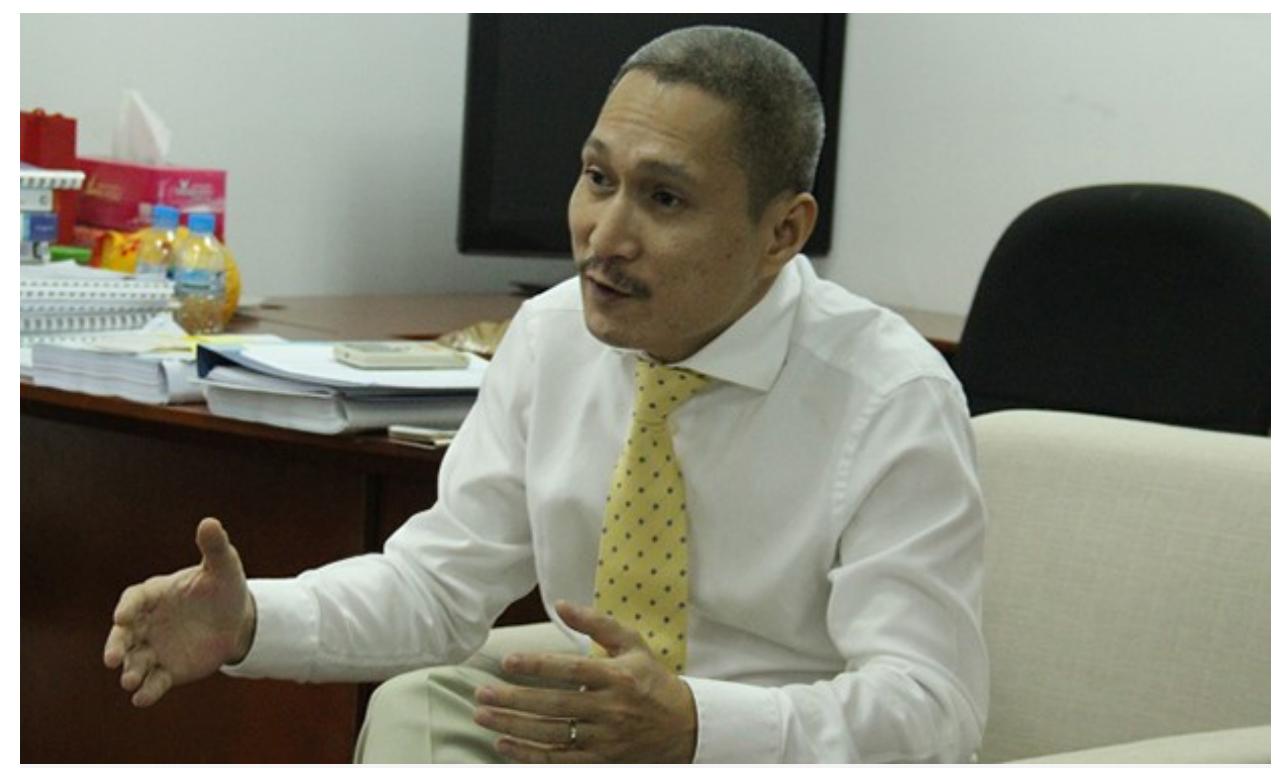

Anh Hoàng cho rằng số lượng nghiên cứu công bố quá thấp, chỉ khoảng 0,3 bài báo/năm/nhà nghiên cứu và sự thiên lệch trong phát triển khoa học tự nhiên và xã hội là hai điểm yếu của người làm khoa học ở Việt Nam.

Lấy ví dụ sống động của danh họa bậc thầy người Hà Lan Vincent Van Gogh chẳng màng tới chuyện bán tranh khi còn 
sống, dù cho ông vốn xuất thân là người buôn tranh và người em trai cũng là nhà buôn kỳ cựu. Anh Hoàng bày tỏ quan điểm: "Ý nghĩa cơ bản của việc làm khoa học cũng như vẽ tranh, viết nhạc, đều xuất phát từ thôi thúc nội tại của bản thân: muốn khám phá thế giới và chứng minh sự tồn tại trong cuộc đời. Nghĩ về tiền thì không còn đúng nghĩa khoa học nữa".

Về câu chuyện tiến sĩ lương 3 triệu đồng, anh Hoàng thừa nhận đó là một rào cản để toàn tâm, toàn ý làm khoa học nhưng đó mới chỉ là một vế của vấn đề. Anh đặt bài toán ngược lại: "Nếu lương 30 triệu/tháng cũng không có gì chắc rằng các tiến sĩ sẽ làm khoa học tốt hơn. Tôi từng biết những người cách đây 30 năm rất nghèo nhưng đến giờ khi có nhà lầu, xe hơi, con đi du học họ vẫn trình bày hoàn cảnh khi nói về chuyện làm khoa học". Giảng viên của FSB và ĐH FPT quan niệm tiền không bao giờ là động cơ của những thành tựu lớn.

Theo anh Hoàng, nhờ một phần ở sức ép của thị trường, sự đòi hỏi cao về làm nghề, giới khoa học trẻ Việt Nam đang tăng cả nhận thức và mức độ tham gia vào nghiên cứu. Anh Hoàng nói: "Người làm khoa học cũng như thợ mộc. Thợ mộc phải đóng bàn ghế đồ dùng, giáo viên phải giảng dạy, thì nhà khoa học phải có công trình nghiên cứu".

Ngọc Dung

Ảnh: FSB 